\title{
Electrochemical Determination of Imidacloprid in Soil Sample Based on Photosynthesized Silver Nanoparticles from Hypnea musciformis
}

\author{
Ganggang Pan ${ }^{1, *}$, Jing Chen ${ }^{1}$ and Jianfang Guang ${ }^{2}$ \\ ${ }^{1}$ Key Lab Efficient Irrigation and Drainage \& Agricultural Soil and Water Environment, Ministry of \\ Education, Hohai University, Nanjing, 210098, Jiangsu, P.R. China \\ ${ }^{2}$ Collage of Water Conservancy \& Hydropower, Hohai University, Nanjing, 210098, Jiangsu, P.R. \\ China \\ *E-mail: pgg999@hhu.edu.cn
}

doi: $10.20964 / 2016.07 .16$

Received: 25 March 2016 / Accepted: 22 April 2016 / Published: 4 June 2016

In this communication, we proposed an eco-friendly chemical route for photosynthesizing silver nanoparticles (Ag NPs) using the extract of red alga Hypnea musciformis extract. The biosynthesized Ag NPs were characterize using SEM, UV-vis spectroscopy, XRD and FTIR. Further study showed the biosynthesized Ag NPs can be applied for electrode surface modification and used for electrocatalytic determination of imidacloprid in the soil sample.

Keywords: Hypnea musciformis; Ag NPs; Biosynthesis; Photosynthesis; Pesticide; Imidacloprid

\section{$\underline{\text { FULL TEXT }}$}

(C) 2016 The Authors. Published by ESG (www.electrochemsci.org). This article is an open access article distributed under the terms and conditions of the Creative Commons Attribution license (http://creativecommons.org/licenses/by/4.0/). 